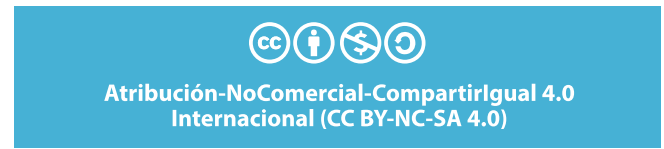

DOI: http://dx.doi.org/10.20983/reij.2022.1.5

\title{
NOTAS SOBRE EL SURGIMIENTO DEL ESTADO MODERNO. EL EJERCICIO DEL PODER SOBERANO DEL ESTADO
}

\author{
Notes on the rise of the modern State. The exercise of the \\ sovereign power of the State
}

\section{Resumen}

El ejercicio del poder soberano es lo que describe al Estado moderno. El surgimiento del Estado moderno es un tema que encaja en el derecho internacional. La posibilidad de ser uno mismo, de ser un Estado que se autogobierne, es lo que describe al Estado moderno y el hecho es que esta nota o característica no puede contarse a lo largo de los tiempos. Es una nota que viene de la Época Moderna en virtud de la cual se tratará de explicar este fenómeno, a partir de una exposición de los hechos históricos que se vinieron presentando y que dieron lugar al llamado Estado moderno, que no debe confundirse con el Estado de derecho.

\section{Palabras clave: Estado moderno; derecho internacional; poder soberano.}

\section{Abstract}

The exercise of the sovereign power is what describes the modern State. The rise of the modern State is an issue that fits into international right. The possibility of being oneself, of being a self-governing State, is what describes the modern State and the fact is that this note or characteristic cannot be counted throughout time. It is a note that comes from the Modern Era by virtue of which an attempt will be made to explain this phenomenon based on an exposition of the historical facts that have been presented and gave rise to the so-called modern State, which should not be confused with the State of law.

Keywords: modern State; international right; sovereign power.

1 Profesor de Derecho de los conflictos y presidente de la Asociación Nacional de Profesores de Derecho Internacional Privado. Miembro activo de la Asadip e investigador nacional Conacyt, Nivel III. ORCID: 0000-0003-0809-5916. 


\section{Introducción}

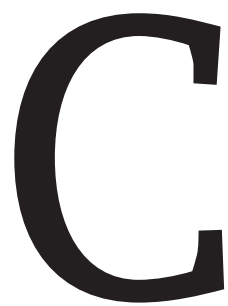

uando hablo de Estado moderno me refiero a un Estado autárquico, que se da sus propias normas. No niego la existencia de Estado con anterioridad. Tan es así que existieron los llamados ciudad-estado. Lo que niego es que hubiesen sido soberanos, salvo en el caso de la Roma imperial. Luego, el Estado moderno es el Estado que puede darse su propio orden jurídico, con libertad, eso es, sin estar sujeto a otro poder.

Lo que me propongo trata de resolver las siguientes interrogantes: ¿cómo es que cada Estado de la comunidad internacional ejerce su poder o competencia en el ámbito internacional?, ¿de dónde le viene este poder? y ¿cómo se delimita?

Para comprender el tema del poder autónomo de cada Estado de la comunidad internacional, es necesario recurrir a los hechos históricos. Solo de esa manera se puede entender el surgimiento del Estado moderno, que fue el que dio pie a que cada Estado pudiera dictar sus leyes con autonomía, es decir, autogobernarse.

Como elemento preliminar, cabe recordar los tres elementos componentes del Estado: gobierno, territorio y poder. Teniendo en mente estos tres elementos trataré de delinear cómo surgió el Estado moderno. ¡Vamos!, cómo surgió cada Estado de la comunidad internacional.

Para entender este fenómeno es necesario partir del surgimiento de cada Estado, a partir de las relaciones internacionales. Solo hay Estados cuando contamos con un derecho internacional. No se comprendería al Estado moderno si omitimos la relación con otros Estados, esto es, el enfoque internacional. 


\section{Primera parte}

\section{Surgimiento del Estado moderno}

\section{Aparición del poder de la Iglesia}

Aunque hubo Estado soberano en la Roma clásica, este se desmoronó con la aparición de la Iglesia cristiana romana y solo volvió a aparecer al surgir el Estado moderno, luego de los Tratados de Paz de Westfalia. A este andar me referiré enseguida, por lo que haré un repaso histórico de los hechos ocurridos.

\section{Fin de la Roma clásica}

Hasta antes de la caída del Imperio Romano de occidente, a manos de los germanos, se habló de un ius civile, esto es, un derecho civil, propio para los que inicialmente residían dentro de la ciudad de Roma, aunque evolucionado al paso del tiempo. Los romanos acostumbraban ejercer su poder sin someterse a nadie. Roma convivió con el ius gentium, creado por los romanos, para tratar a aquellos que no residían dentro de Roma. ¡Vamos!, se implementaron dos sistemas jurídicos. Tiempo después, el emperador Antonino Caracalla logró unificar ambos sistemas y todos los habitantes del mundo conocido quedaron bajo un mismo orden jurídico. Un mismo Estado.

A partir de la Edad Media, que se inicia con la caída de la Roma occidental, se enfrentaron un derecho impuesto por los seres humanos (derecho positivo) con el dictado por Dios (por medio de la Iglesia) y en el que este último, normalmente, salió adelante; fue el de la Iglesia. Se instauró un gobierno teocrático.

Con la caída del Imperio Romano, nos explica Raymond Gettel (1959):

... la creencia preponderante en el derecho natural, como conjunto de máximas fundamentales de justicia que existen fuera del hombre, y la convicción de una ley divina, revelada por Dios, hicieron imposible el reconocimiento del derechopositivo, humano, en cuanto obra y ejecución de la autoridad del Estado. ${ }^{2}$

Incluso, afirma Gettel, la Iglesia y el gobierno civil se fusionaron. Lo que de ahí en adelante continuó no ha sido fácil de entender. Guterman (2019), por su parte, explica que:

Lo que quizá sea más importante en este estudio es precisar el marco de referencia. Para el historiador no puede ser otra cosa que las invasiones, vistas como un amplio movimiento de cambio social y político. No se debe dudar en utilizar el enfoque jurídico, pero nunca se debe olvidar que el sistema de derecho personal estuvo históricamente condicionado. ${ }^{3}$

2 Raymond Gettel, Historia de las ideas políticas, México, Editora Nacional, vol. I, 1959, p. 298.

3 Simeon Leonard Guterman, El principio de la personalidad del derecho en los inicios de la Edad Media: un capítulo en la evolución de las instituciones e ideas jurídicas occidentales, México, UNAM, 2019, p. 7. 
De alguna manera, el derecho romano sobrevivió, aunque transformado en un derecho vulgarizado. Propio de lo que fue estimado como un derecho romano eclipsado. ${ }^{4}$ Aquí hay que recordar que previo a la caída del Imperio de Occidente, este fue dividido. Una parte, la que sobrevivió, fue llevada a oriente, a Constantinopla.

\section{El Imperio de Oriente}

Con la caída de la Roma de occidente, quien asumió el poder fue la Iglesia católica romana.

El Imperio de Oriente o Bizantino, que también se autollamó romano, fue esplendoroso, porque fue en este en donde estuvo Justiniano, más conocido por la compilación que hizo del derecho romano. Los bizantinos fueron desde ese momento los más sobresalientes, aunque eclipsados por occidente.

\section{El gobierno de la Iglesia}

Con la caída de Roma, la Iglesia asumió un poder teocrático sobre toda la tierra. Se trata de un dato histórico de mayor importancia que no debe de perderse de vista.

A la caída, el obispo de Roma se proclamó obispo de obispos y asumió el mando con el nombre de papa. Sostuvo ser el representante de Dios en la Tierra. Esto es, como el director general de la nueva religión, pero también de los seres humanos,

4 Beatriz Bernal Gómez, Historia del Derecho: cultura jurídica, México, 2010, pp. 85 y ss. sosteniendo la tesis de que todos son "hijos de Dios".

La estructura que esa Iglesia siguió fue la misma del Imperio Romano que había caído: un jefe único en el vértice, príncipes hacia abajo (cardenales), arzobispos, obispo y una gran cantidad de vasallos creyentes (el pueblo) y laicos (no necesariamente pertenecientes a una religión), agrupados en torno a los obispos y hasta diáconos. Surgió así, una agrupación política organizada en sentido vertical, con el papa en la cúspide.

El poder o dominio del papa no se circunscribió a lo meramente espiritual. Tampoco se encerró en un específico territorio, sino sobre todos los creyentes de la religión, así como en los no-creyentes, cualquiera que fuese el lugar en que se encontrasen. Esto es, el territorio (ojo, el territorio) no fue lo importante para ejercer el poder, sino los gobernados (el pueblo). El elemento territorio (parte del Estado moderno) no fue tomado en cuenta. El foco principal estuvo sobre el pueblo, elemento que se superpuso al territorial. El pueblo, en especial los súbditos, fue el elemento sobre el que se asentó el orden jurídico de la Iglesia. Para esta, el ser ciudadano o tener un origo perdió importancia frente a ser hijo de Dios y salvar su alma.

De esta manera, el poder de los gobernantes sobre un territorio fue eliminado: su poder y los territorios. 
Lo que a la Iglesia le importó fue toda la población mundial (orbis et orbi), no una ciudad-Estado delimitada en su territorio. Circunscribirse a gobernar un territorio no estuvo en el plan del papa: su gobierno no se delimitó a un territorio específico. La Iglesia nunca se fijó un límite territorial. Para esta todo mundo fue su súbdito o vasallo (feligreses, creyentes y no-creyentes). Se sostuvo que todo mundo es hijo de Dios y el papa, su representante. Todavía en la actualidad se dice: "el Papa es el vicario de Dios”. La idea impuesta desde el inicio fue que el reino más importante está después de nuestra muerte, cuando subamos al cielo. ¿Para qué preocuparnos de los problemas terrenales cuando lo más importante está en lo espiritual? El terreno de las ideas fue el dominante y el más importante.

En occidente, el gobernante de la Iglesia romana quedó al frente de "toda la humanidad". Así, se habló de una "república cristiana”, como Hobbes le llamó. Una república para la que no importó el territorio, sino solo aquellos a los que en términos políticos les llamaríamos súbditos, entendidos como hijos de Dios, siendo el papa su representante en la tierra.

Las tesis de Agustín de Hipona, que habló solo de la ciudad de Dios, diferente a la terrenal, no fue aceptada o, al menos, ignorada por la misma Iglesia, que, afirmó, no solo tiene el poder espiritual, sino también el terrenal; fue la máxima con la que se gobernó.

\section{Las invasiones y asentamientos}

Fueron las invasiones y asentamientos germanos los que precipitaron la caída del Imperio de Occidente, y que se continuaron produciendo hasta el fin del primer milenio. El enfrentamiento entre razas o fusión de las mismas, dio lugar a un derecho personal, más conocido como personalidad de las leyes.

Han sido muchos los investigadores que se han preguntado el porqué de una ley personal, pero todos nos llevan a las invasiones. La ley de los germanos acompañaba a la persona al lugar al que fuere; incluso, fueron recíprocos con los romanos.

Cuando los romanos permitieron el asentamiento de los germanos en la zona norte del imperio, estos pidieron que sus costumbres fuesen reconocidas. De esta manera, hubo un derecho para los pueblos germanos, estimado como un derecho propio de la personalidad de las leyes. Esos germanos, aun cuando estuviesen fuera de su lugar, exigían se tomase en cuenta sus costumbres. Y así fue.

El pueblo germano acostumbraba reconocer las costumbres de cada uno de sus pueblos o tribus. Este enfoque fue aprovechado por la Iglesia y sus intereses, como veremos. Entre los germanos también hubo la posibilidad de reconocer las costumbres de los judíos, sin esperar nada a 
cambio de estos. Pero esto no fue retomado por la Iglesia.

Las leyes personales procuraron hacer a un lado las del clásico derecho romano, enfocadas en los cives. Las personales fueron las predominantes y, salvo excepción, las territoriales tenían la posibilidad de imponerse. ${ }^{5}$ El Código de Eurico (propio de los visigodos) y el Breviario de Alarico nos muestran las diferencias en el derecho aplicable. Este último fue una compilación realizada por orden del rey para tratar de esclarecer las costumbres contradictorias habidas hasta entonces, que provenían de otros textos romanos.

Este devenir en los hechos, tan complejo, compone esta parte de la historia, para la que Guterman (2019) expresa:

Al principio sólo hubo una ley personal, la de los romanos. La primera evidencia se encuentra en el prefacio al derecho romano de los visigodos que reconoce expresamente los derechos de los súbditos romanos en el reino visigodo. [...] bajo los visigodos los romanos gozaron del beneficio del derecho romano entre ellos tratándose de los casos civiles y, en grado limitado, en materia penal. ${ }^{6}$

5 Simeon Leonard Guterman, El principio de la personalidad del derecho en los inicios de la Edad Media: un capítulo en la evolución de las instituciones e ideas jurídicas occidentales, México, UNAM, 2019, p. 1.

6 Simeon Leonard Guterman, El principio de la personalidad del derecho en los inicios de la Edad Media: un capítulo en la evolución de las instituciones e ideas jurídicas occidentales, México, UNAM, 2019, pp. 27 y 29.

\section{Agrega que:}

Es posible trazar tres o cuatro respuestas generales a la pregunta sobre cómo y dónde se originó el sistema de leyes personales. La primera respuesta, popular por su simplicidad, y por haber respondido a un sentimiento profundamente arraigado, es que el principio tuvo un origen germánico. ${ }^{7}$

En fin, no solo fue la influencia de la Iglesia en su afán de tener bajo sí a todo el mundo, sino que en el desarrollo del derecho también influyeron las necesidades generadas por las invasiones, que van desde la caída del Imperio de Occidente y las subsecuentes durante el primer milenio. La tradición hasta antes de las escuelas estatutarias fue la ley personal y se explica por las diferencias de costumbres y necesidades del momento.

\section{Las Cruzadas}

Aunque el Imperio de Oriente continuó, al igual que la religión imperante en ese lugar (la Iglesia ortodoxa), nunca estuvo muy conforme con la Iglesia romana, pues, aunque cristiana, no reconoció al papa romano como su superior jerárquico.

7 Simeon Leonard Guterman, El principio de la personalidad del derecho en los inicios de la Edad Media: un capítulo en la evolución de las instituciones e ideas jurídicas occidentales, México, UNAM, 2019, p. 15. 
Hacia los siglos x y xi, el Imperio de Oriente comenzó a ser amenazado por los musulmanes. La Iglesia ortodoxa se vio forzada a pedirle auxilio al papa romano. Este, trató de auxiliar a los de oriente enviando ejércitos para combatir a los musulmanes por medio de las llamadas "guerras de las Cruzadas". En el fondo, lo que el papa Urbano deseaba era someter bajo su poder a la Iglesia ortodoxa. Agréguese, los problemas entre latinos y bizantinos. El hecho fue que no siempre les fue bien a los cruzados, pues, finalmente, Constantinopla cayó bajo el poder musulmán en 1453 (poco antes del descubrimiento de América).

Fue, con motivo de las Cruzadas, que se expandió el comercio, muy importante en el derecho internacional y muy desarrollado por los comerciantes (Lex Mercatoria), a partir de las grandes compañías. ${ }^{8}$ Hecho que dio lugar al enriquecimiento de varias ciudades y monarcas, como para pelear y luchar por alcanzar un poder terrenal, disputándoselo a la Iglesia.

\section{La Paz de Constanza}

En 1183 Federico I Barbarroja firmó un tratado entre él, como emperador, y las ciudades lombardas, en el que se le reconoció el poder a Barbarroja para recoger, para sí, ciertos derechos de peaje, pero, a la vez, se

8 Jorge Alberto Silva, "Resurgimiento de la Lex Mercatoria: la regulación de las relaciones comerciales internacionales", Jorge Alberto Silva (compilador), Estudios de Lex Mercatoria, México, UNAM, 2006. le reconoció a cada ciudad el derecho de construir sus murallas y de gobernarse a sí mismas conservando sus propias costumbres. Con esto, cada ciudad comenzó a contar con sus propios estatutos, esto es, un derecho propio. Las leyes de aquellas ciudades fueron creciendo, polarizando a todos los habitantes de Europa, dando lugar a diferencias entre cada ley o costumbre de cada pueblo. Las ciudades-Estado habían hecho su aparición.

Cabe resaltar el aumento de compilaciones de costumbres de todo tipo y en muchos pueblos. Los señores feudales propiciaron sus propios ordenamientos o leyes para proteger su tierra y mantener sometidos a sus vasallos.

Por su parte, los comerciantes compilaron sus costumbres, que han pasado a la historia; de estas vendrán después lo actuales códigos de comercio. El hecho es que legisladores, Parlamento o Asamblea Legislativa, como cuerpo especializado y profesional en dictar leyes, como hoy las conocemos, es difícil de encontrar en épocas previas.

Cabe comentar el amplio fraccionamiento de Europa, en donde, casi de hecho, cada ciudad va a tener su rey, quien normalmente pelea contra los vecinos, pero que, también, logra asociaciones políticas casando a sus hijos e hijas. Se inicia con los reyes, que reinan pero no gobiernan con autonomía. Connotado fue el matrimonio por conveniencia entre Isabel y Fernando 
(los reyes católicos) siglos después, dando lugar al surgimiento de lo que hoy es España, todo a partir de una alianza política.

\section{Carlo Magno}

Antes de la caída del Imperio de Oriente —repito, el de Oriente-, en la Iglesia romana, el papa León III, especialmente, fue depuesto como papa y encarcelado. Logró huir hacia las Galias a pedir auxilio. Los germanos, bajo el mando de Carlo Magno, tomaron su defensa y lucharon con la bandera católica para que León recuperara el trono. Carlo Magno regresó al papa depuesto, lo sentó en la silla papal y León, en premio, le otorgó el nombramiento de emperador.'

De esta manera, por la sola palabra del papa se creó un imperio. Surgió así, por disposición del papa, el Sacro Imperio Romano Germánico (800), al que todo el mundo debería estar sujeto. Germánico, porque Carlo era de Germania. Al papa le asistieron algunas razones, que no solo fueron de agradecimiento: entre otras, hacer a un lado:

a) El Imperio de Oriente, con el que no congeniaba;

b) Contar con un gobierno o fuerza que lo protegiera de los lombardos, que

9 Carlo Magno fue parte del grupo de Clodoveo, el primer germano del grupo franco que se convirtió al cristianismo. Clodoveo fue el rey de los francos. Uno de los mayordomos (algo así como un primer ministro), de estos reyes, es el antecedente de Carlo Magno. no eran cristianos, y que estaban enseguida de Roma;

c) Hacer efectiva la religión en todo el mundo.

De ahí en adelante, todos los monarcas y emperadores solo pudieron ser coronados por el papa o con su consentimiento. Todos tuvieron como meta la conversión de todo el mundo al catolicismo. Carlo Magno sometió el poder civil al religioso. Esa fue una meta de todos los continuadores del poder civil, incluyendo a los llamados reyes católicos, Carlos V, Felipe II y todos los que lo siguieron, incluido Fernando VII (en la época de la Independencia de México). Estos soberanos sometieron a los habitantes del continente americano, pues su meta fue cristianizar a toda la población a partir de que cayó Tenochtitlan. Gobernaron al amparo de la teoría del derecho divino, la cual Dios les había concedido a los reyes.

Continuó el sistema de la personalidad de las leyes, que quiere decir no estar sometido a la ley de un territorio, sino a la del lugar de su origen; incluso, por medio de las capitulares (decretos de Carlo Magno), ${ }^{10}$ inspiradas en la unidad del mundo y sus pobladores, en las que el elemento territorial no jugó un papel de importan-

10 Simeon Leonard Guterman, El principio de la personalidad del derecho en los inicios de la Edad Media: un capítulo en la evolución de las instituciones e ideas jurídicas occidentales, México, UNAM, 2019, p. 49. 
cia ${ }^{11}$ ni tampoco se reconoció "ningún otro sistema ni personalidad política" (no a los Estados)..$^{12} \mathrm{El}$ hecho es que, en términos reales, el poder territorial de Carlo Magno no cubrió todo el mundo.

Aquí hay que tomar en cuenta que, en la zona carolingia, la mezcla de razas, de los germanos, con las de descendientes de los romanos vino a conducir a un derecho más personalista, sin que, por ello, se abatiesen algunos resabios territorialistas feudales, que comenzaron a surgir y que se presentaron con mayor fuerza en el segundo milenio.

Al concentrar el papa todo el poder para sí, todos los monarcas tuvieron que someterse a él. La humillación de Canossa (1077) nos muestra el poder alcanzado por el papa, al someter al emperador Enrique IV, luego de su excomunión.

\section{Los enfoques estatutarios. Segundo milenio}

Coincidentemente, por esas épocas se inician los estudios de derecho en general y la aparición de las tesis o doctrinas estatutarias, sobre todo, porque las leyes de los pueblos comenzaron a diferenciarse entre sí en sus contenidos. Tales tesis van a ir variando al paso del tiempo, cruzando con las de la personalidad de las leyes, que venían desde la caída del imperio, para

11 Simeon Leonard Guterman, El principio de la personalidad del derecho en los inicios de la Edad Media: un capítulo en la evolución de las instituciones e ideas jurídicas occidentales, México, UNAM, 2019.

12 Raymond Gettel, Historia de las ideas políticas, México, Editora Nacional, vol. I, 1959, p. 299. llegar a tesis más territorialistas, especialmente con el desarrollo del sistema feudal, en el que cada señor dará preferencia a sus propios criterios para la protección de sus tierras. La llamada lex fori fue sostenida por estos señores y se refiere a la ley de la tierra del señor feudal. Un elemento de importancia que retoma el actual Estado moderno.

Contribuirán al desarrollo de las tesis estatutarias las universidades recién creadas al amparo del análisis del corpus iuris civilis justinianeo, haciendo renacer un derecho romano ajustado o ambientado a la época, que se pensaba aún en vigor. No obstante, se le tomaría como derecho común, esto es, supletorio al de cada principado.

Cinus de Pistoia (uno de los grandes juristas de la época) diferenciaba las ciudades regidas por mero derecho común y las ciudades con derecho común y estatutos. De manera que, si en una ciudad regía solo el derecho común, este se imponía en cualquier otra ciudad, aunque en esta otra existiesen estatutos. Parece que fue Bártolo de Sassoferrato (otro gran jurista) el que le dedicó más espacio a la extraterritorialidad de la ley, incluyendo en su doctrina los estatutos odiosos (una excepción a la ley extraña) que deberían de ser rechazados (lo que hoy llamamos leyes que vulneran el orden público).

Cabe decir que las tesis sobre conflicto de leyes no eran propiamente internacio- 
nales, pues el Estado soberano, como hoy lo conocemos, no había surgido. Más bien, los "conflictos" estudiados se referían, principalmente, a las costumbres (coutumes) de cada pueblo (ciudades-Estado) y los medios para resolver las diferencias al amparo de las leyes romanas, que se estimaban como de derecho común. En estas tareas sobresalió la Universidad de Bolonia, que no estaba sometida al poder del papa tan fuertemente como la de París, por lo que sus profesores gozaron de mayor libertad para expresarse.

Uno de los máximos estatutarios fue Accursio, quien se inclinó por la ley personal al interpretar la lex cunctos populus, que encontró en los textos justinianeos, y sostuvo que al lugar al que fuese una persona su ángel de la guarda lo acompañará; esto es, la ley de lugar de su origen va con ella. Esta precisión la hizo al realizar una intrépida interpretación de los textos que se encontraban en el corpus iuris civilis romano. ${ }^{13}$ Poco antes, Karolus había sostenido que statutum non ligat nisi subditos (la ley no obliga a los súbditos), que pugna con la lex fori.

En resumen, las ideas hasta aquí expresadas parecen decir que como regla gene-

13 Jorge Alberto Silva, "Los orígenes del derecho conflictual”, La Lex Cunctos Populus, Revista Mexicana de Derecho Internacional Privado y Comparado. También se publicó como "La Lex Cunctos Populus. Un impulso al razonamiento iusinternacional privatista contemporáneo", en Heurística Jurídica, Ciudad Juárez, UACJ, año I, núm. 2, enero-junio de 2011. Igualmente, en Rapsodia Jurídica. Selección de Textos Jurídicos, Ciudad Juárez, UACJ, 2020 (artículo 04). ral se aplica la ley del origo, esto es, la ley del lugar de origen de la persona como ley personal, aunque, excepcionalmente, la ley del foro. Una explicación que resulta diferente a lo que se presenta en la actualidad.

\section{Bulas papales}

El papa Alejandro VI, autoestimado como el director y guía del mundo, al año siguiente del descubrimiento de América, repartió el continente americano entre españoles y portugueses, como lo atestiguan las bulas inter caetera, dudum siquidem y otras (1493). Repartió territorios solamente entre los monarcas que se habían sometido a su poder y que prometieron cristianizar a los pueblos y sus naturales bajo su poder. En premio por el descubrimiento y promesa de fidelidad al papa, Fernando e Isabel recibieron el título de Reyes Católicos por parte del papa.

Carlos V, el emperador, apoyó fuertemente el poder del papa, reconociéndole no solo un poder espiritual, sino también el temporal.

\section{Mengua del poder temporal de la Iglesia} Con las guerras de Reforma religiosa y la Contrarreforma religiosa, la fuerza papal comenzó a debilitarse. La Contrarreforma no logró sostener el poder papal; la Iglesia católica vino hacia abajo al producirse una mengua en su poder político, a pesar del apoyo de Carlos V. Desde entonces, 
hasta ahora, no recuperó el poder que se autoatribuyó desde la caída del Imperio Romano de occidente.

Lutero y Maquiavelo habían expresado que era necesaria la separación entre la Iglesia y el Estado (el poder civil). Curiosamente, Lutero sostuvo la supremacía de la ley territorial, representada por cada gobernante civil; respaldó, igualmente, el derecho divino de los reyes y admitió un derecho a la resistencia. Calvino, por su parte, por haber sido jurista, hizo lo propio, afirmando, incluso, que la Iglesia debía sujetarse al derecho. No se opuso a la Iglesia romana, pero dijo que esta debía circunscribirse al poder espiritual, no al terrenal. Habló de las asambleas representativas como necesarias (lo que sería el cuerpo de legisladores actuales). En general, sostuvieron que el poder civil debía pertenecer a los príncipes, no al emperador, y que la Iglesia no debía entrometerse con el poder terrenal.

Cabe destacar que entre quienes lucharon por la reforma religiosa no solo hicieron al papa a un lado del poder terrenal, sino también a los emperadores. Robusteciendo el poder de los reyes, en especial, el de los príncipes alemanes. En otros lugares, el poder de los reyes condujo al absolutismo, como en Francia, o en España con los Habsburgo.

Entre otras razones que provocaron la caída de la Iglesia (incluso acabar su poder temporal) encontramos:
- La corrupción de la Iglesia católica, sus ansias de poder y fortuna;

- La reforma religiosa que dio lugar a la religión protestante con Lutero y, luego, con Calvino (el movimiento de Reforma);

- El surgimiento de la religión anglicana, con Enrique VIII, en Inglaterra;

- El rechazo de los ortodoxos para someterse al papa;

- Durante esa época se produjo un enfrentamiento entre reyes y príncipes contra el emperador y contra el papa; al igual que entre reyes y señores feudales;

- Los intelectuales de la época cuestionaron que el papa tuviese un poder temporal;

- El odio contra la Iglesia católica por parte de los protestantes, sobre todo por los asesinatos de los hugonotes, seguidores de Calvino. Se estima que la Noche de San Bartolomé fueron asesinados en Francia unas veinte mil personas por no ser católicas;

- Acrecieron las luchas entre los Borbón, en Francia, y los Habsburgo, en España y Austria. Cuestiones religiosas entre ambos;

- La cuestión más importante: surgieron las guerras más lamentables de ese momento, especialmente la Guerra de los Cien Años y la de los Treinta Años. Una, por la lucha entre España y los Países Bajos; y la otra, por 
factores de poder, especialmente religiosos y deseos de libertad;

- Grandes pensadores comenzaron a escribir para sostener al príncipe y al poder terrenal de los monarcas, excluyendo al poder papal y el del emperador.

Hasta el momento en el que la Iglesia detentó el poder temporal no había aparecido el Estado, que partiese de un poder territorial soberano. En su surgimiento, gravitó fuertemente la aparición de la imprenta, la difusión de los textos de Lutero, así como la traducción de la Biblia, traducción prohibida por el papa.

Las luchas armadas fueron largas y desgastantes para solucionar el problema en el que todos los países europeos se vieron envueltos, incluyendo a España, que ya se había apropiado de América. La Iglesia católica, en su contrarreforma, reaccionó creando los tribunales de la Santa Inquisición. El saqueo de las riquezas del continente americano apoyó a Carlos V en su misión de apoyo al papa. Se creó la Sociedad de Jesús (jesuitas) para apoyar al papa, en la que destacó Belarmino, sosteniendo el poder papal..$^{14}$

\section{Paz de Westfalia}

En busca de una solución y al agudísimo problema de las guerras, se iniciaron con-

14 Luchas posteriores entre los Habsburgo frente a los virreyes condujeron, con José Bernardo de Gálvez, a la expulsión de los jesuitas. versaciones, que durante varios años dieron lugar a la llamada "Paz de Westfalia" en 1648.

Los Tratados de Westfalia delimitaron el poder a la Iglesia romana, negándosele que tuviese un poder temporal. Seguramente uno de los puntos de mayor importancia.

Hasta antes de Westfalia, el derecho romano, jvamos!, un derecho más universal, fue el principal orden jurídico. La codificación justinianea continuaba, pero también, en el oeste, cierta colección de usos y costumbres, aunados a las reglas de la Iglesia, estimadas de superior jerarquía. Hasta entonces, el Derecho romano fue la ratio scripta. La Iglesia auspició este derecho, pues, según su interpretación, congregaba a la "república cristiana".

Hasta antes de este momento, el papa fue conocido como el orbis dominus, el señor del mundo, pero los escritos políticos comenzaron a desquebrajar ese poder temporal, cuestionándole al papa dicho poder.

La legitimidad del papa quedó cuestionada. Esa legitimidad se sentaba en el ius gentium, que comenzó a tambalearse. Para entonces, se empezó a hablar de un derecho interestatal, que después vino a llamarse internacional.

A partir de las negociaciones surgieron o, mejor dicho, se robustecieron, los gobiernos civiles, que quedaron delimitados a un espacio territorial. Con estos surgió el territorio como elemento del Estado. Los 
gobiernos civiles, inicialmente monarcas, adquirieron un poder autónomo (al hacer a un lado a la Iglesia), conformándose la población con los súbditos de un gobernante civil o rey, súbditos que se encontraban dentro del territorio que por ese entonces fijó la Paz de Westfalia. ${ }^{15}$

Aún no se habló de nacionalidad, lo que vendría poco después. Aunque la Reforma religiosa dio lugar a un patriotismo nacional, dando fin a la unidad de la Iglesia y una reorganización en Europa, como lo afirma Raymond Gettel (1959). ${ }^{16}$ Observen ustedes que, para este momento, ya están presentes los tres elementos del Estado: territorio, poder y población.

De hecho, los juristas e historiadores (la historiografía) están de acuerdo que fue aquí cuando surgió el llamado Estado moderno, caracterizado por ser soberano. Fue aquí cuando surgieron los Estados nacionales, aunque monárquicos. Se habló de soberanía hasta que estos aparecieron. En palabras de Gettel (1959): “... para llegar a la formación de un cuerpo de derecho internacional, es necesario que se reconozca la realidad de los Estados centralizados, libres e independientes de toda sujeción extraña". ${ }^{17}$

El profesor José Bremer lo dice con acierto: "la Paz de Westfalia sentó las bases ju-

15 Raymond Gettel, Historia de las ideas políticas, México, Editora Nacional, vol. I, 1959, pp. 371 y ss.

16 Raymond Gettel, Historia de las ideas políticas, México, Editora Nacional, vol. I, 1959, p. 247.

17 Raymond Gettel, Historia de las ideas políticas, México, Editora Nacional, vol. I, 1959, p. 300. rídicas para el reconocimiento y el funcionamiento de una nueva correlación de fuerzas en Europa". ${ }^{18}$

Para entonces, el territorio no será parte de la Iglesia, sino hasta el Pacto de Letrán (1929), en el que el dictador Benito Mussolini le entregó a la Iglesia católica cuarenta y cuatro hectáreas, que es lo que hoy conforma el Estado Vaticano. Mediante la Paz de Westfalia se logró:

- Delimitar las fronteras físicas;

- Delimitar las facultades del imperio o emperador con los Estados alemanes;

- Establecer un orden legal que regulase la convivencia entre las tres religiones: catolicismo, luteranismo y calvinismo. ${ }^{19}$

Se estableció que las creencias religiosas no pueden influir en los hospitales, la sucesión ni los cementerios. Esto no aplicó a España, Francia y Suiza, porque Suiza era protestante; España, católica; y Francia tenía al cardenal Richelieu, que combatió a los protestantes, pero delimitó a los católicos. Basta recordar que Dumoulin (a inicios del siglo xiv), uno de los grandes internacionalistas, apoyó al calvinismo,

18 Juan José Bremer, De Westfalia a Post-Westfalia: hacia un nuevo orden internacional, Universidad Nacional Autónoma de México, Instituto de Investigaciones Jurídicas, 2013, p. 10.

19 Juan José Bremer, De Westfalia a Post-Westfalia: hacia un nuevo orden internacional, Universidad Nacional Autónoma de México, Instituto de Investigaciones Jurídicas, 2013, p. 10. 
opositor al papa, así como a la regla locus regit actum para casi todo tipo de negocios, rechazando la ley personal.

A consecuencia de Westfalia, se consolidaron los Estados dinásticos. Tuvieron más fuerza y con estos aparecieron los Estados. Cambió la llamada "república cristiana" hacia la aparición de los Estados soberanos. Y, de ahí en adelante, el ciudadano fue el importante: se le reconoció un derecho a razonar por sí solo (libertad de conciencia) y (más tarde) hasta elegir a sus gobernantes.

Gran parte de esto, se le debe a las tesis luteranas, que hablaron de este tipo de libertad. También contribuyeron Francisco Suárez y De Vitoria, para quienes el poder político reside en la comunidad; incluso, que el papa no debe intervenir en política. Se robustecieron los estudios de la Teoría del Estado. Hablaron Maquiavelo y Bodin, y se le dio forma al concepto de soberanía, que afirmó una monarquía fuerte, suprema y única en cada Estado. Para Bodin, "la formación de la ley es la función principal de la soberanía”. ${ }^{2}$

Durante las guerras que precedieron a Westfalia, aparecieron los escritos de Hugo Grocio, quien definió al Estado como "una sociedad perfecta de hombres libres que tiene por objeto la regulación del derecho y el bienestar común”. ${ }^{21}$ Su mérito

20 Raymond Gettel, Historia de las ideas políticas, México, Editora Nacional, vol. I, 1959, p. 304.

21 Raymond Gettel, Historia de las ideas políticas, México, Editora Nacional, vol. I, 1959, p. 316. principal, anota Gettel (1959), "radica en haber creado un sistema de derechos y obligaciones jurídicas, aplicables a las relaciones de los Estados.... ${ }^{22}$

En suma, el derecho de gentes ya no fue un derecho común para todos, sino un derecho de cada Estado, un derecho de entre los Estados.

Luego de los Tratados de Westfalia surgieron los trabajos de Thomas Hobbes, reconceptualizando el tema de la soberanía (1651), bajo la cual concibe las leyes como un sometimiento al soberano, identificado como el que ejerce el poder civil, afirmando que el poder religioso debe estar sometido al civil.

Aunque el absolutismo fue predominante en Inglaterra, separada de la zona continental, ya se veía en ese lugar una representación parlamentaria. Contrastada con el amplio poder de Luis XIV en Francia, como sabemos.

Bremer (2013) apunta que "los tratados de Westfalia van a cumplir con una función de estímulo de todas estas tendencias en la evolución del derecho de gentes a un derecho interestatal". 23

A partir de entonces, se sustituyó la organización del Sacro Imperio Romano Germánico, creado por el papa, por Estados independientes, en los que ya no fue

22 Raymond Gettel, Historia de las ideas políticas, México, Editora Nacional, vol. I, 1959, p. 317.

23 Juan José Bremer, De Westfalia a Post-Westfalia: hacia un nuevo orden internacional, Universidad Nacional Autónoma de México, Instituto de Investigaciones Jurídicas, 2013, p. 24. 
posible la injerencia de la Iglesia en sus asuntos. De igual manera, el amplio poder del emperador, protegido por el papa, se vino abajo. De los Tratados de Westfalia surgieron trescientos cincuenta Estados, de los cuales muchos pequeños se agruparon en torno a Austria-Hungría, Brandemburgo, Prusia y otros. De ahí, hasta el fin de la Primera Guerra Mundial.

Ante la caída del poder de los Habsburgo, se colapsó la unidad del Sacro Imperio Romano Germánico y cada Estado surgió ejerciendo un poder que no había ostentado antes. Los monarcas españoles lucharon por que las nuevas ideas no entraran a las colonias americanas; en especial, hasta antes de las reformas borbónicas. Sostuvieron contra viento y marea las tesis papales e impidieron el avance de la ciencia y la libertad de conciencia, rechazando una conciencia nacional (inexistente), así como la creación de ciudadanos libres y Estados nacionales. Los tribunales inquisitoriales procuraron detener su avance. De hecho, así continuó la Iglesia en México hasta la Guerra de Reforma. En gran medida, las notas que caracterizaron a la Edad Media continuaron en la América Española o Nueva España. Todavía en México, el Código Civil de Oaxaca, de 1828, le reconoció a la Iglesia católica una supremacía.

A partir de entonces surgió el Estado territorial y soberano, y con ello, la llamada territorialidad o exclusividad de las leyes por sobre las leyes personales. Lo anterior, a partir del derecho de cada Estado de poder legislar por sí mismo y ejercer su propio poder sobre todos. No se creó un solo Estado, sino una gran cantidad de Estados. Se escindió el poder terrenal en varios poderes. A partir de aquí van a surgir las tesis nacionalistas (siglo xIX).

A no mucho tiempo de ahí, las restituciones de las tierras eclesiásticas se comenzaron a dar. Pero, en México, hasta la Ley Lerdo de 1856 (Ley de Desamortización de las Fincas Rústicas y Urbanas de las Corporaciones Civiles y Religiosas de México).

Una recapitulación de los efectos de la paz de Westfalia

Hasta antes de Westfalia no hubo una reunión de reinos para resolver problemas generales. Lo que hubo fueron sínodos o congresos convocados por la Iglesia. ${ }^{24}$

Antes de los convenios de Westfalia la legitimidad y pertenencia a un conglomerado, para no llamarlo Estado soberano, se entendía como la sujeción a una dinastía, en la que cada monarca era el "dueño" de sus plebeyos o súbditos; ${ }^{25}$ incluso, podían heredar su reino a sus hijos (dinastías hereditarias), incluida la tierra y su población, pero todo bajo la aceptación y supervisión

24 Juan José Bremer, De Westfalia a Post-Westfalia: hacia un nuevo orden internacional, Universidad Nacional Autónoma de México, Instituto de Investigaciones Jurídicas, 2013, p. 29.

25 Conforme a la Real Academia de la Lengua súbdito es: "sujeto a la autoridad de un superior con obligación de obedecerle". 
del papa. Todavía, en la actualidad, los reinos sobrevivientes, llamados eufemísticamente de monarquía parlamentaria (de caricatura u ornamento), se transfieren a los descendientes de los monarcas, aunque ya no dirijan un gobierno (reinan, pero no gobiernan), como actualmente suele ocurrir en algunos países. Como sea, al final de Westfalia confluyeron:

- La territorialidad o exclusividad, como elemento que legitimó el poder de los gobernantes;

- La secularización de la política, que abandonó los lazos religiosos, salvo en el caso español y sus colonias;

- Se impulsaron las teorías y la creación de expresiones filosófico-políticas;

- La libertad para pensar y escribir fue en aumento;

- La nacionalidad aún no había surgido; el sentido de pertenencia era inexistente. Por lo tanto, tampoco apareció la llamada soberanía popular. Esta fue una creación de cada gobierno para asegurar la lealtad del pueblo gobernado (el principal elemento del Estado).

Adolfo Miaja de La Muela (1972) es claro cuando explica que:

... la situación empieza a cambiar cuando termina la guerra de los Cien años con Inglaterra y se afianza el poder real de Luis XI frente a los señores feudales: el derecho de aubana desaparece progresivamente, el comercio exterior encuentra una seguridad de la que antes se carecía, y aparece como clase social directiva la de los hombres de leyes, en quienes los monarcas encuentran eficaces auxiliares en su lucha con los nobles. Además, Carlos VII ordena que se redacten las costumbres de las distintas regiones y, aunque el mandato tarda en ser cumplimentado, cuando por fin se eleva a escrito el derecho consuetudinario, las discrepancias legislativas se hacen más visibles, dando ocasión a que los juristas se ocupen de los conflictos resultantes de estas disposiciones. ${ }^{26}$

A partir de Westfalia cada Estado creado:

- Alcanzó un poder pleno e independiente;

- Pudo elaborar sus propias leyes, sin sujetarse a reglas o autoridades externas. Los temas de estado civil, capacidad de las personas, sucesión mortis causae, ya no le correspondieron a la Iglesia;

- El Estado pudo impartir justicia; a la Iglesia se le excluyó. No ocurrió lo mismo en España y sus Colonias. Prueba de ello es que el Código Civil de Oaxaca (en el México independiente) le dejó a

26 Adolfo Miaja de la Muela, Derecho internacional privado, t. I, Madrid, Gráficas Yagües, 1972, p. 111. 
la Iglesia católica el control de la capacidad y el estado civil de las personas, en el que no metería la mano el gobierno civil.

- Se alcanzó una administración del gobierno civil propia.

Nada de esto se pudo haber logrado con el papado. En gran medida surgió un pacto de tolerancia entre todos los Estados soberanos que surgieron.

Aquellos tratados fueron lo que podemos llamar una "constitución mundial", que vinieron acatándose por cada Estado y jueces. Hasta inicios del siglo XIX, se acostumbraba citarlos con frecuencia.

\section{Segunda parte}

\section{Elementos complementarios}

Doctrinas posteriores a la paz de Westfalia A consecuencia del surgimiento del Estado moderno, se produjo un cambio en las ideas y el teocentrismo fue reemplazado por el humanismo. Apareció la imprenta; las ideas se difundieron ampliamente; llegaron los grandes pensadores. En general, me referiré en las siguientes líneas a los efectos producidos.

La pintura, la escultura, las grandes obras literarias, se deslindaron de los dictados de la Iglesia. La Teoría Heliocéntrica surgió y la tierra dejó de ser el centro del universo con Copérnico, Galileo y Kepler. La revolución científica fue impulsada por
Newton. La Edad Moderna y el Renacimiento dieron lugar al cambio.

El punto central a discutir fue si el papa está por encima de los reyes o al revés. $\mathrm{Al}$ final, ganó la segunda tesis.

Montesquieu hizo su aparición y vino a sostener la necesidad de contar con tres poderes, uno de los cuales es -o debe ser- el encargado de elaborar las leyes, y otro, de aplicarlas, y otro que solo dirigiera (por su mente no pasaron los gobiernos imperiales y menos los presidencialistas). Rechazó que la potestad legislativa y la ejecutiva, se reuniesen en una misma persona, con lo cual el poder omnímodo del monarca fue rechazado para generar hombres especializados en crear leyes (no gente especializada en aplaudir y festejar al monarca).

Sentada la regla de que cada Estado puede legislar por sí mismo y contrariando el cuento y tradición del "rey legislador", se vino también a sostener - como hasta ahora-que el derecho aplicable, en lo general, es el del propio foro (OJO: el de un territorio), salvo que este mismo orden jurídico admita la toma en consideración de un acto o ley extranjera. Se rechazó la tesis que afirmó que existía un derecho común de la humanidad: un derecho natural y universal, emergiendo las tesis del derecho positivo.

A estas tesis confluyeron, inicialmente, parte de las tesis estatutarias francesas, pero especialmente las holandesas, cuyos 
juristas eran calvinistas. Aunque hay que decir que, ya antes, Bertrand D’Argentré había acelerado el enfoque territorial; incluso, colaboró como legislador en Las costumbres de Bretaña. Sus tesis influyeron en las holandesas. Su enfoque estuvo más orientado a lo feudal. Aquí aparecieron las fuertes figuras de Pablo y Juan Böet (padre e hijo), así como Ulrico Huber, que también impulsaron el tema de la soberanía de cada Estado.

En 1661 se implementó en la Universidad de Heidelberg la primera cátedra sobre derecho natural y de gentes, teniendo como titular a Samuel Pufendorf. Igualmente, se habló de la necesidad de los seres humanos para ajustar su conducta a la razón.

A partir de aquí, los doctrinarios del derecho internacional privado (DIPr) comenzaron a afianzar las tesis territorialistas o exclusivistas, reforzando, con ello, la soberanía de cada Estado. Fue aquí donde aparecieron otros grandes ius privatistas, como Ulrico Huber, que rechazó cualquier acto jurídico proveniente de otro Estado al propio. Decía: si un juez toma en cuenta el derecho de otro lugar, lo hace por cortesía (comitas gentium). Fue aquí donde apareció la tesis de los llamados derechos adquiridos.

Los holandeses, sometidos a Carlos V, se separaron del reino de España (en la época de Felipe II), reforzaron la constitución del Estado e hicieron a un lado la intromisión de los franceses. Contando ya con un Es- tado, y un propio gobierno, desarrollaron, simultáneamente, un sistema de normas para regir entre los Estados, a partir de la igualdad entre estos. El derecho internacional hizo su aparición a partir de reglas de derecho.

Con la convocatoria a los Estados Generales y la Revolución francesa, se llegó a contar con legisladores del pueblo. Ahora, había que tomarse en cuenta su voluntad y no la del monarca. El movimiento francés fue muy duro, pero cambió el curso de la historia.

\section{Democracia}

Con la Revolución francesa el poder de la Iglesia, emperadores y reyes, se vino totalmente abajo, para hacer surgir el respeto a los ciudadanos, a sus derechos humanos y a empezar a tomar en cuenta el poder del pueblo.

Con la revolución también vino la democracia, así como el nacionalismo (sentimiento de pertenencia a un Estado). Casi de inmediato vino la independencia de las colonias americanas, creando varios Estados, etcétera. Las doctrinas antimonárquicas impulsaron la democracia, todo a partir de tesis, como la del contrato social, que afirmó una razón común para la convivencia y un rechazo al absolutismo. Las tesis contractualistas supusieron la voluntad de todos los súbditos (una potestas) para conformar un ente que los gobernara. 
Inicialmente, el poder soberano se le atribuyó al monarca (durante el absolutismo), quien podía crear la ley e, incluso, designar a sucesores (su familia); ${ }^{27}$ posteriormente, el poder soberano fue reclamado por el pueblo, etapa en la que nos encontramos. Por ahora, la democracia parlamentaria condujo al fin de las monarquías absolutistas. La lucha contemporánea es entre quienes dirigen un Estado y el pueblo que desea se le tome en cuenta. Tal es el momento histórico por el que cruzamos. Aún subsisten "reyezuelos" y dictadores que dicen tener la razón absoluta, afirmando ser infalibles y rechazando todo tipo de opiniones; incluso, desconociendo el poder jurídico que se le atribuye a cada uno de los tres poderes de los que habló Montesquieu.

Aunque emergió el clamor por una democracia en Francia, tal manifestación se reiteró a partir de la independencia de Estados Unidos de América cuando los ciudadanos de trece diferentes colonias lograron independizarse de los poderes que los subyugaron, constituyendo un gobierno civil y estableciendo sus propios legisladores. Con esto surgió el nacimiento de una Constitución para cada Estado (a la manera como hoy la conocemos).

Esta actitud se diseminó y despertó el germen de la democracia como opuesta a un gobierno autoritario, y la posibilidad

27 Clásica ha sido la dinastía de los Borbón y los Habsburgo. de contar con una Constitución, ${ }^{28}$ que proclamase una propia soberanía, esto es, un propio Estado. Fueron los derechos y reivindicaciones a favor del pueblo los que surgieron y dieron lugar a la democracia, que, por desgracia, tampoco se ha desarrollado en su totalidad.

Luego de la independencia de Estados Unidos de América cada Estado del continente americano alcanzó su independencia, sosteniendo su propia soberanía y construyendo su propia Constitución, creando su propio Poder Legislativo y Judicial, dando lugar a sus propias leyes. Los Estados europeos, principalmente Francia, Italia y Alemania, alcanzaron luego su unidad territorial como Estados soberanos. Surgieron los espíritus nacionalistas, esto es, personas con sentido de pertenencia a un Estado: "soy mexicano, soy francés, soy italiano”.

Hoy en día, cada Estado se proclama soberano y con una Constitución que se declara texto legal supremo para cada Estado. Cada Estado puede legislar y decidir cómo relacionarse con otros Estados de la comunidad internacional. Aun, incluso, cuando algunos Estados están sojuzgados por un poder dictatorial. Actualmente, en la legislación intervienen los intereses propios del Estado o de los gobernantes en turno, especialmente los intereses particulares que estos últimos defienden.

28 David M. Kennedy, The American Pageant: A History of the Republic, Toronto, D. C. Heath and Company, 1979. 
Finalmente (siglo xIx), aparecen las grandes codificaciones en cada Estado, todas surgidas desde el interior de cada uno, procurando impulsar la propia voluntad interna y no una universal o una papal. La época de la gran codificación mexicana vino con el gobierno de Porfirio Díaz. La codificación del derecho no fue un movimiento antiguo, sino de la época contemporánea (siglo xix). Esta ha contribuido a impulsar el Estado de derecho, dando por terminada la época en que había que apelarse a los textos justinianeos y canónicos. El fenómeno produjo la sistematización de los textos legislados, pero, especialmente, el surgimiento de un derecho nacional. Los legisladores aparecieron en escena. Hasta antes, eran el emperador, los reyes o los señores feudales los que dictaban el contenido del derecho u ordenaban la compilación de las costumbres existentes.

Las leyes de cada Estado comenzaron a aparecer. Tal vez la de mayor magnitud fue el Código Civil napoleónico (1804). La ley personal derivada de enfoques metafísicos terminó y solo se aceptó una ley personal cuando el Estado así lo admita. El derecho natural terminó para dar paso a un derecho positivado.

Principios de política legislativa de cada Estado frente a los demás

Hasta antes de que aparecieran las leyes positivadas, como producto de legisladores, con carácter de generalidad y abstrac- ción, se solía resolver cada caso partiendo del sentido de justicia que se creía más conveniente. Aunque, después de los estudios universitarios que se iniciaron con los estatutarios, los jueces solían seguir a Bártolo de Sassoferrato, nombrado consiliarius y cuyas opiniones fueron estimadas como leyes.

En efecto, en general, no existieron leyes con las características generales como las conocemos (generales, abstractas e impersonales); más bien, se trató de expresiones de los grandes juristas que se inspiraron en viejos textos romanos, costumbres o sentencias de la época, que, al glosarlos, le adicionaban sus propios comentarios (posglosadores). Muchos de estos comentarios surgieron de respuestas a jueces $\mathrm{u}$ otras personas, a manera de responsa prudentium (respuestas), indicando lo aconsejable.

Actualmente, podemos hablar de los principios de política legislativa de cada Estado frente a los demás, inferidos de una legislación de fuente interna y respeto a los Estados entre sí. Presuponen que las normas de competencia legislativa son indirectas. Con algunos ajustes y acoplamientos, siguiendo a Miaja de la Muela (1972), podría decirse que la política legislativa de cada Estado acoge, entre otros, los siguientes principios:

a) Principio de exclusividad, que significa que cada Estado es el que establece 
sus propios supuestos de competencia. Supone que su ley de fuente interna indica cuáles casos o supuestos son de su competencia; incluso, que solo este Estado es el que puede decidir si toma en cuenta un acto o ley extranjera. ${ }^{29}$

b) Principio de unilateralidad, que significa que ningún órgano o tribunal de un Estado puede atribuirle competencia a otro Estado.

c) Principio de efectividad o eficacia, según el cual no debe reconocerse una resolución extranjera cuando en el propio foro resulte imposible la ejecución de lo que prescribe.

d) Principio de posibilidad de internacionalización de las normas intraestatales, que significa llevar al ámbito internacional las propias normas exclusivistas de fuente interna cuando así lo desea el Estado. Es decir, que una ley intraestatal puede ser llevada para resolver un problema internacional.

Reglas de competencia en la esfera internacional

Con la constitución del Estado moderno, presumimos que cada Estado ejerce su poder o soberanía en forma racional, evitando invadir la esfera jurídica de otros Estados. Al efecto, se ha establecido a ni-

29 Jorge Alberto Silva, La norma de competencia judicial exclusiva internacional. La perspectiva mexicana”, Perspectiva Jurídica, núm. 2, Guadalajara, Universidad Panamericana, 2014. vel convencional y en el derecho de fuente interna que solo se reconocerá el poder o competencia asumida en el extranjero, siempre y cuando se hubiese asumido o se ajuste a las reglas de competencia reconocidas en la esfera internacional. Lo anterior, supone la tesis del equilibrio internacional. El problema queda en el significado de la expresión "reglas de competencia reconocidas en la esfera internacional".

Salvo lo que especifique un tratado internacional, México controla la competencia directa asumida en el extranjero, procurando que sea compatible con las reglas de competencia en la esfera internacional (arts. 564 del CFPC; 1347-A frac. III del CCom mexicanos). Lo anterior significa que México no reconoce lo actuado en un Estado extranjero, que estime exorbitante o abusivo.

Aunque solo referido a tribunales y sentencias extranjeras, el Código Federal de Procedimientos Civiles (CFPC) prescribe que un tribunal mexicano solo reconocerá el poder establecido por un tribunal extranjero cuando lo hubiese asumido por razones que resulten compatibles $o$ análogas con el derecho mexicano. ¡Vamos!, para la definición de su contenido hay que seguir las reglas de compatibilidad o la analogía. ${ }^{30}$ En este sentido, la compatibilidad

30 Sobre el particular, el cfpc prescribe: "Art. 564 CFPC: Será reconocida en México la competencia asumida por un tribunal extranjero para los efectos de la ejecución de sentencias, cuando dicha competencia haya sido asumida por razones que resulten compatibles o análogas con el derecho nacional, salvo que 
o la analogía con el poder establecido en México será la pauta para definir la competencia en la esfera internacional.

En el apartado convencional internacional, a tales reglas alude la Convención Interamericana sobre Competencia en la Esfera Internacional para la Eficacia Extraterritorial de las Sentencias Extranjeras (art. 2), el Convenio entre los Estados Unidos Mexicanos y el Reino de España sobre Reconocimiento y Ejecución de Sentencias Judiciales y Laudos Arbitrales en Materia Civil y Mercantil (art. 5), así como la Convención Interamericana sobre Competencia en la Esfera Internacional para la Eficacia Extraterritorial de las Sentencias Extranjeras (art. 1). Aúnase a lo anterior lo prescrito en la Carta de las Naciones Unidas y sus propósitos, al preconizar la "igualdad soberana", al igual que en la Carta de la OEA, cuando alude a la defensa de la soberanía, su respeto e integridad.

Estas reglas de competencia reconocidas en la esfera internacional, se definen en su contenido, generalmente, a partir del derecho consuetudinario, sin olvidar las reglas de compatibilidad o la analogía a que me he referido. Esto es, como lo decía Jellinek, para definir estas reglas no falta la voluntad soberana del Estado. Es decir, porque rara o difícilmente se encuentran explicitadas en tratados o convenios internacionales; más bien, cada Estado es el

se trate de asuntos de la competencia exclusiva de los tribunales mexicanos". que unilateralmente las impone, decidiendo hasta dónde se admite que otro Estado de la comunidad internacional interfiera en la esfera jurídica propia.

Las "reglas de competencia en la esfera internacional" prescriben, desde el enfoque de cada Estado en lo particular, los límites al poder de otros Estados, no solo tratándose de su función jurisdiccional y ejecución de sus decisiones, sino también de la legislación de esos Estados que le otorgan poder a sus autoridades.

En fin, con la constitución de los Estados modernos triunfa y se impone una ley territorial, aunque no exclusivista. En este sentido, una ley territorial significa aplicar el propio orden jurídico sustantivo, incluida la prescripción que admite el derecho extranjero. ${ }^{31} \mathrm{El}$ hecho es que, al paso del tiempo, se ha hecho necesaria la toma en consideración del derecho extranjero, incluidos los actos generados al amparo del mismo, lo que no necesariamente significa tomar en consideración una ley personal, a la manera que se entendió en la Edad Media.

31 Jorge Alberto Silva, "La territorialidad o exclusividad del orden jurídico estatal. Algunas precisiones semánticas”, Revista Mexicana de Derecho Internacional Privado y Comparado, vol. 27, diciembre, 2010. Igualmente, en Rapsodia Jurídica. Selección de Textos Jurídicos, Ciudad Juárez, Universidad Autónoma de Ciudad Juárez, 2020 (artículo 06). 
Control de la competencia legislativa asumida en el extranjero

Carecemos de una Constitución mundial que distribuya el poder de legislar para cada Estado de la comunidad internacional. Carecemos de un tribunal de competencias a nivel mundial; por ello, cada Estado es el que controla el poder de cada Estado. La mayor parte de ese poder, se rige conforme al derecho consuetudinario internacional o leyes de fuente interna, que definen la compatibilidad o la analogía con el poder propio.

La facultad, obligación o prohibición para legislar puede derivar de algunos convenios internacionales, que generalmente: i) obligan o prohíben a un Estado establecer cierto tipo de leyes; o a ii) sujetarse a leyes y convenios que controlan indirectamente las leyes extranjeras, condicionándolos para que se sujeten a las "reglas de competencia en la esfera internacional".

Obligación y prohibiciones para expedir leyes

Sobre la obligación de un Estado para expedir cierto tipo de leyes, con un específico contenido, así como establecer organismos especiales, encontramos la Convención Interamericana sobre Tráfico Internacional de Menores, que establece que:
“... los Estados Parte se comprometen a: [ ...] Establecer por medio de sus Autoridades Centrales mecanismos de intercambio de información sobre legislación nacional, jurisprudencia, prácticas administrativas, estadísticas y modalidades que haya asumido el tráfico internacional de menores en sus respectivos Estados (Art. 8)".

Igualmente, el Convenio sobre Obtención de Alimentos en el Extranjero establece que:

La Parte Contratante cuya legislación imponga restricciones a la transferencia de fondos al extranjero concederá la máxima prioridad a la transferencia de fondos destinados al pago de alimentos o a cubrir los gastos a que den lugar los procedimientos previstos en esta Convención (Art. 10).

En cuanto a prohibiciones, basta recordar que el Pacto Internacional de Derechos Económicos, Sociales y Culturales no reconocerá la restricción legal de los derechos establecidos en este convenio. Por igual, la Convención Internacional sobre la Eliminación de Todas las Formas de Discriminación Racial obliga a derogar o anular "las leyes y las disposiciones reglamentarias que tengan como consecuencia crear la discriminación racial o perpetuarla donde ya exista”. 
Control indirecto del poder de legislar

Salvo casos especiales establecidos en algunos tratados cada Estado es libre para legislar y reconocer leyes y decisiones derivadas de esas leyes extranjeras. Carecemos de una Constitución mundial que distribuya el poder para legislar entre los Estados. Kelsen habla de un derecho consuetudinario conforme al cual cada Estado, se reduce a su territorio y poder.

Una cuestión de interés consiste en saber cómo se controla la competencia legislativa asumida en el extranjero. El hecho es que ningún Estado puede controlar de manera directa esa competencia asumida; por ejemplo, no sería posible un amparo contra leyes extranjeras. No obstante, en forma indirecta cabe la posibilidad de ejercer un control. Consiste en no reconocer o rechazar la competencia legislativa asumida en el extranjero al dictar una resolución, como suele ocurrir en el caso de leyes extraterritoriales (long arm statutes), que paso a explicar adelante.

El art. 571 del CFPC prevé que no se podrá reconocer una sentencia extranjera cuando esta hubiese contrariado "reglas reconocidas en el derecho internacional que sean compatibles con las adoptadas por este Código", esto es, la ley mexicana.

En el fondo cada Estado es el que se preocupa por vigilar una "razonabilidad" en la legislación extraestatal de los otros Estados. Así, cuando el poder de un Estado se amplía demasiado otro Estado es el que lo neutraliza, desconociendo los efectos de la ley del Estado que ha ampliado su poder. Esta facultad para neutralizar reside (normalmente) en los jueces, no en el Poder Ejecutivo. ${ }^{32}$

\section{Long arm statutes}

Me detengo en los long arm statutes (leyes de brazo largo) del derecho de Estados Unidos, que permiten asignar poder o competencia legislativa a ese país. Se piensa que el asunto o litigio ha de resolver guardacontactos mínimos con el foro de otro país. $\mathrm{Al}$ amparo de estas leyes, sus autoridades pueden conocer de daños cuando estos se hayan producido en otra nación. Se trata de un criterio competencial en cierta forma conectado con el forum shopping. Uno de los casos destacados fue la Ley estadounidense de Solidaridad Democrática y Libertad Cubana de 1996 (Libertad), más bien conocida como Ley Helms-Burton, que afectó a Europa, Canadá y Estados Unidos, quienes reaccionaron mediante leyes en contra.

En México, esta ley fue neutralizada mediante la Ley de Protección al Comercio y la Inversión de Normas Extranjeras que Contravengan el Derecho Internacional (DOF, 23 de octubre de 1996). Pero, también puede neutralizarse cualquier otra ley extranjera al estimar que la misma ofende el

32 Jorge Alberto Silva, "La precisión de la competencia internacional: la perspectiva del Estado mexicano”, Direito do comércio internacional $=$ Derecho del Comercio Internacional, núm. 4, DeCita, Zavalia, 2005. 
orden público mexicano o que prohíja un fraude a la ley.

\section{Competencia exorbitante}

¡Vamos!, un tribunal mexicano no reconocerá el poder o competencia legislativa ejercido por un Estado extranjero cuando el poder que hubiese asumido el Estado extranjero sea calificado como exorbitante. Lo exorbitante corresponde a un poder ejercido que se estima va más allá del que le pudiera corresponder, según las normas de competencia reconocidas en la esfera internacional. A falta de tratado, la calificación de exorbitante recae en el Estado al que se le presenta una sentencia, para que la reconozca y ejecute, especialmente, en sus jueces. Exorbitante es un adjetivo que, al ser referido a la competencia asumida, implica que la facultad de conocer es exagerada o desmedida.

La expresión proviene de ex y orbis: lo que está fuera de su órbita. Lo exorbitante se estima desmedido e irracional; fuera de lo normal o racional. La competencia exorbitante, abusiva o excesiva es la que rebasa los límites razonables o normales de la competencia o poder que pudiera serle reconocida a un Estado de la comunidad internacional. Para los publicistas, el Estado es observado como un sujeto del derecho internacional; les preocupa el reconocimiento como Estado, su personalidad y sus funciones en la comunidad internacional; incluso, diferencian sus funciones "hacia dentro" y "hacia fuera", esto es, como gobierno en sus relaciones internas y les interesa en sus relaciones internacionales. En gran medida, se han preocupado por marcar los límites de cada Estado como medio de lograr la convivencia. ${ }^{33}$

\section{Codificación convencional internacional}

El DIPr había venido siendo un derecho de fuente interna. No fue sino hasta muy avanzado el tiempo cuando se decidió establecer en convenios internacionales esa temática. En el ámbito convencional internacional no fue sino hasta fines del siglo xix cuando en los Países Bajos y en Lima, se trató de atender la codificación del DIPr, principalmente por medio de tratados. A partir de entonces, se inició una etapa codificadora, que en principio fue lenta, pero con un súbito despertar a partir de la Segunda Guerra Mundial, especialmente debido a los auspicios de los organismos internacionales creados en ese momento y otros que han venido surgiendo. De esta manera, han aparecido en la escena mundial organismos como la Conferencia de La Haya, UNCITRAL, UNIDRoIT, etcétera.

\section{Conclusiones}

Llego al final de esta exposición, pero conviene concretar lo que he expuesto:

33 Matthias Herdegen, Derecho internacional público, Instituto de Investigaciones Jurídicas y Fundación Konrad Adenauer, México, 2005. 
1) A partir del Estado moderno cada Estado alcanzó un poder soberano para dictar sus propias leyes, dentro de las que caben las propias del Dipr. Las leyes de ningún Estado están sujetas al poder de otro Estado ni a las viejas reglas de la Iglesia.

2) Ha sido el derecho consuetudinario el que le ha marcado ciertos límites a cada Estado para rechazar sus leyes extraterritoriales.

3) Cada Estado es el que cuida que el poder de otro Estado no se exceda. En el caso de que se exceda, reacciona rechazando el reconocimiento y efectos de la ley estimada como exorbitante. Tarea que, normalmente, les compete a los jueces de cada Estado.

4) La soberanía de los Estados ha venido evolucionando. De la soberanía que detentaban los reyes, esta ha venido abajo tendiendo a una democracia del pueblo, que aún está por verse en muchísimos lugares del mundo y en nuestro país. Los representantes populares, como suele llamárseles, aún continúan sirviendo al "monarca" del momento y sus intereses.

\section{Referencias}

Bernal Gómez, Beatriz, Historia del Derecho: cultura jurídica, México, 2010.

Bremer, Juan José, De Westfalia a Post-Westfalia: hacia un nuevo orden internacional, Uni- versidad Nacional Autónoma de México, Instituto de Investigaciones Jurídicas, 2013. Gettel, Raymond, Historia de las ideas políticas, México, Editora Nacional, vol. ı, 1959.

Guterman, Simeon Leonard, El principio de la personalidad del derecho en los inicios de la Edad Media: un capitulo en la evolución de las instituciones e ideas jurídicas occidentales, México, UNAM, 2019.

Herdegen, Matthias, Derecho internacional público, Instituto de Investigaciones Jurídicas y Fundación Konrad Adenauer, México, 2005.

Kennedy, David M., The American Pageant: A History of the Republic, Toronto, D. C. Heath and Company, 1979.

Miaja de la Muela, Adolfo, Derecho internacional privado, t. I, Madrid, Gráficas Yagües, 1972.

----, "La norma de competencia judicial exclusiva internacional. La perspectiva mexicana”, Perspectiva Jurídica, núm. 2, Guadalajara, Universidad Panamericana, 2014.

Silva, Jorge Alberto, "La precisión de la competencia internacional: la perspectiva del Estado mexicano", Direito do comércio internacional $=$ Derecho del Comercio Internacional, núm. 4, DeCita, Zavalia, 2005.

-----, "Resurgimiento de la Lex Mercatoria: la regulación de las relaciones comerciales internacionales", Jorge Alberto Silva (compilador), Estudios de Lex Mercatoria, 2006.

----, "La territorialidad o exclusividad del orden jurídico estatal. Algunas precisiones semánticas”, Revista Mexicana de Derecho 
Internacional Privado y Comparado, vol. 27, diciembre, 2010. Igualmente, en Rapsodia Jurídica. Selección de Textos Jurídicos, Ciudad Juárez, Universidad Autónoma de Ciudad Juárez, 2020 (artículo 06).

-----, "Los orígenes del derecho conflictual, La Lex Cunctos Populus", Revista Mexicana de Derecho Internacional Privado y Comparado. También se publicó como "La Lex Cunctos Populus. Un impulso iusinternacional pri- vatista contemporáneo", en Heurística Jurídica, Ciudad Juárez, UACJ, año I, núm. 2, enero-junio de 2011. Igualmente, en Rapsodia Jurídica. Selección de Textos Jurídicos, Ciudad Juárez, Universidad Autónoma de Ciudad Juárez, 2020 (artículo 04). Luchas posteriores entre los Habsburgo frente a los virreyes condujeron, con José Bernardo de Gálvez, a la expulsión de los jesuitas. 